other children' and many were adept at negotiating risks and benefits in order to 'fit in'. Chronic illness - to a greater or lesser extent - was 'always there' but it was often successfully backgrounded through careful planning. The children actively foregrounded their achievements and focused on 'getting on' with being a child. This was not always easy. Whilst there was evidence of much resilience, this took effort and imagination from the children and their families. The children's parents/ carers provided an important role in supporting the children's ability to self-manage their illness.

Conclusion Brokering and self-management were evident in the stories children told about themselves. The use of photo-elicitation gave the children control over those facets of their lives they wanted to discuss and share with the researchers. We found it a useful tool to discover those things that were important to the children and how they were active in ensuring that they could say 'I can.....'

\section{G235 HOLDING CHILDREN FOR CLINICAL PROCEDURES; AN ETHICAL CONSIDERATION OF THE EVIDENCE}

1,2 L Bray, 2,3 B Carter, ${ }^{4} \mathrm{~J}$ Snodin. ${ }^{1}$ Evidence-Based Practice Research Centre, Edge Hill University, Ormskirk, UK; ${ }^{2}$ Children's Nursing Research Unit, Alder Hey Children's NHS Foundation Trust, Liverpool, UK; ${ }^{3}$ School of Health, University of Central Lancashire, Preston, UK; ${ }^{4}$ Faculty of Health and Social Care, Edge Hill University, Ormskirk, UK

\subsection{6/archdischild-2015-308599.228}

Aim This presentation will review current evidence on clinical holding and discuss how holding children, for clinical procedures against their wishes, can create tension between children's rights and agency and health professionals' duty to care and to act in the best interests of children in their care.

Method A narrative synthesis approach used systematic procedures to search and appraise the current empirical evidence relating to children being held for procedures within an acute children's care setting. Children in mental health, dental, primary care and anaesthetic settings were excluded from the review.

Findings Empirical evidence demonstrates that children are frequently held for procedures to be completed within acute care settings. The delineation between holding and restraint is poorly defined. Children's protests and distress are reported as taking lower precedence in a decision to hold a child for a procedure than either clinical need or the interests of the adults present. Parents and health professionals expressed feelings of distress, uncertainty, guilt and upset associated with clinical holding. Despite this, alternatives to holding are not always explored and health professionals maintain that the child's best interests are served by a procedure being completed quickly at the expense of short-term distress; the end justifiying the means. This approach neither takes into consideration the possible long-term psychological consequences of holding or restraining children for nonurgent procedures nor how their rights and agency are protected by the adults charged with advocating for them. Evidence suggests that current practice is weighted towards an adult centred approach and that consideration needs to be given to how practice can be tipped towards a child centred approach.

Conclusion Although children are reported as being frequently held for clinical procedures, there is very little quality empirical data or critical ethical debate to inform practice. The lack of robust evidence and clear definitions of what constitutes holding perpetuate this being an almost invisible and taken for granted part of children's care within acute settings.

\section{G236} BRIDGING THE GAP; FROM FAMILY CENTRED CARE TO FAMILY - ENABLED CARE?

P Curtis, A Northcott, J Reid. School of Nursing and Midwifery, University of Sheffield, Sheffield, UK; Sheffield Children's NHS Foundation Trust, Sheffield, UK

\subsection{6/archdischild-2015-308599.229}

Aims The concept of family centred care (FCC) has informed the provision of care to hospitalised children since the late 1980s. However, there is a well acknowledged gap between the principles and practice of FCC. Differences between the expectations of care providers have been demonstrated as has nurses' reticence to share decision-making and cede control to family members. Family members, in turn, have pointed to the lack of support received from nurses. This paper presents findings from a study which sought to explore the potential for care contracts to support family - enabled hospital care for children.

Methods A 10 month, focused ethnographic study was carried out in 2 medical and 2 surgical wards in one Children's Hospital in the North of England. Data, focusing upon activities of daily living and the administration of oral medication, were generated via observation, interviews and focus group discussion with 144 family members (children aged up to 15 and their parent/s) and 65 nurses and Health Care Assistants. All data were subjected to thematic analysis.

Results Although parents generally considered it their 'duty' to provide basic care for their children while in hospital, they did not necessarily know what they were 'allowed' to do or how they might achieve this. This role confusion was particularly significant during acute, short stay hospitalisations. Nurses recognised the vital role that parents' play in care provision and considered it their responsibility to control and direct negotiations with family members. Both parents and nurses valued informal aspects of care negotiation and neither considered formal contracts to be the way forward.

Conclusions There remains clear evidence of a gap between the principles and practice of FCC, particularly during one-off and short stay hospitalisations, which account for a significant proportion of all admissions. This paper will conclude by suggesting approaches that may enable parents' participation in their child's care that could also be, on the basis of our findings, acceptable to nurses.

\section{G237 FAMILY-CENTRED CUBICLES? ISSUES ASSOCIATED WITH DELIVERING AND RECEIVING CARE IN CUBICLES}

${ }^{1}$ A Northcott, ${ }^{1} \mathrm{P}$ Curtis, ${ }^{2} \mathrm{~J}$ Reid. 'School of Nursing and Midwifery, University of Sheffield, Sheffield, UK; ${ }^{2}$ Sheffield Children's NHS Foundation Trust, Sheffield, UK

\subsection{6/archdischild-2015-308599.230}

Aims Spatial aspects of hospitals have received scant attention in research on Family Centred Care (FCC). Presently, cubicles are used predominantly to isolate patients that present an infection risk or that require a heightened level of observation. Though shared bays remain a common feature on children's wards, new builds tend to increase the number of cubicles at the expense of bays. This paper explores the experiences and expectations of nurses and family members as they provided and received care in hospital cubicles.

Methods A 10 month, focused ethnographic study was carried out in 2 medical and 2 surgical wards in a Children's Hospital in the North of England. Data, focusing upon activities of daily living and the administration of oral medication, were generated 
via observation, interviews and focus group discussion with 144 family members (children aged up to 15 and their parent's) and 65 nurses and Health Care Assistants. All data were subjected to thematic analysis.

Results Families receiving cubicle-based care appreciated the privacy afforded, but parents could feel isolated and bored. Parents were reluctant to leave their children in cubicles unsupervised. Parents in bays valued the informal supervision provided by both nurses and other parents and some children appreciated the social aspect of being around other patients. Nurses expressed concerns about the additional workload that could be associated with cubicle-nursing, finding it difficult to 'get away' from parents isolated from the rest of the ward.

Both nurses and parents expressed practical and medical concerns about increased numbers of cubicles in future ward configurations. A predominance of cubicles was thought to threaten the (highly valued) informal aspects of care and was expected to negatively affect dynamics between parents and nurses. Nurses were also concerned that their peer relations and team-working would be undermined.

Conclusions While family members saw advantages to cubicles in terms of privacy and enhanced resources, both parents and nurses raised concerns that a preponderance of cubicles may be detrimental to FCC. This paper will conclude by suggesting key issues that need to be recognised and addressed in planning for cubicle-based care.

\section{G238 "SAFETY HUDDLES": MULTIDISCIPLINARY VIEWS REGARDING THE PURPOSE AND EFFECTIVENESS OF A NOVEL PAEDIATRIC SITUATIONAL AWARENESS TOOL}

J Adams, R Conn, R Gohil. International and Private Patient Division, Great Ormond Street Hospital NHS Trust, London, UK

10.1136/archdischild-2015-308599.231

Aim Following an audit in 2012, which identified variability in the recognition and escalation of deteriorating patients, Safety Huddles were introduced, utilising a Childrens' Early Warning Score (CEWS), to enhance situation awareness.

Huddles are scheduled, regular multi-professional meetings, no longer than ten minutes, held in the clinical environment alongside an interactive electronic patient board. The sickest and most at risk patients (CEWs $>2$ ) are identified, prompting immediate and appropriate escalation. Four additional risk factors (family concerns, high risk therapies, clinicians' gut feeling and communication concerns) further identify patients as 'watchers'.

Huddles provide:

- Optimum safety through elimination of avoidable harm

- Greater empowerment and accountability of all staff through shared decision making

Our aim was to evaluate the attitudes and understanding of front-line staff regarding the purpose and effectiveness of Huddles, 18 months on.

Methods A voluntary, anonymous online survey was disseminated to staff across 3 clinical areas ( 2 wards, 1 outpatients). Ethical approval was not required.

Results 41 responses were returned. Respondents included 2 consultants, 4 registrars, 24 nurses, 1 nursing student, 1 healthcare assistant, 2 pharmacists and 5 interpreters.

The majority rated their understanding regarding the purpose of the Huddle as "good" (51\%) or "excellent" (41\%). 88\% described the Huddle as an "important aspect" of their work,
98\% no longer requiring reminders to attend. Subjectively, the Huddle led to improvements in: Team Communication (95\%), Patient/carer involvement (63\%), Staff support (80\%), identification of deteriorating patients (93\%) and timely escalation (90\%). $83 \%$ felt better informed about patients not specifically allocated to their care. $50 \%$ felt Huddles should occur with increased frequency.

Crucially, 93\% felt enabled to have their concerns heard.

Problems identified included punctuality of start times and occasional non-attendance of doctors, which subjectively lessened the value of the Huddle.

Conclusion Huddles are regarded as useful by the vast majority of staff and are an inclusive, empowering, non-hierarchical method of information sharing regarding patient safety. Our findings have been shared with all staff and suggested modifications are being considered.

Huddles are now being introduced across UK 12 sites as part of the SAFE collaborative of RCPCH.

\section{G239 UNDERSTANDING THE SPIRITUAL AND RELIGIOUS NEEDS OF YOUNG PEOPLE WITH CANCER AND THEIR FAMILIES TO ENHANCE HOLISTIC CARE}

${ }^{1} \mathrm{P}$ Nash, ${ }^{1} \mathrm{~K}$ Darby, ${ }^{2} \mathrm{~S}$ Nash. ${ }^{1}$ Centre for Paediatric Spiritual Care/Chaplaincy, Birmingham Children's Hospital, Birmingham, UK; ${ }^{2}$ Midlands CYM, St John's College, Nottingham, UK

\subsection{6/archdischild-2015-308599.232}

Aim To identify spiritual and religious needs of adolescent oncology patients and their families with the intention of providing an evidence base for appropriate spiritual and religious care interventions to be developed in a future study.

Methods Small scale phenomenological study, 9 patients, 7 parents, semi-structured interviews with initial approach made by the lead nurse, 2 staff focus groups, thematic analysis of data by multidisciplinary team and tested out with staff in a focus group. A systematic literature review demonstrated the lack of research in this field.

Results Spiritual needs were clustered under the following headings: protection vs autonomy; desire to make a difference; personal issues including loss, privacy, finding a new normal; relationships and attitude including the need to be listened to and opportuniites for empowerment and consent where they could have control; environment including a need for conducive physical and emotional space and a focus on building community; difficult emotions and resilience; need for supportive presence; cultural differences. Religious needs were ritual; hope; questioning and doubt; worldview; language; balance between parent and patient's needs. Inverted transition was noted as an issue to explore further.

Conclusion Practice implications include; need for ongoing assessment and appropriate assessment strategies; articulating spiritual care practices and opportunities; offering normalising activities; importance of culture setting, building community and enhancing the environment; providing space for parents to express emotion and loss; self care for staff; education on religious beliefs and impact on care. A process of inverted transition was noted where young people who would usually be becoming more independent were thrust back towards a dependence on their parents who were often very present on the wards. Perhaps the most valuable thing that can be offered to patients and their families are acts of kindness and 